\title{
MENGUPAYAKAN PEMIKIRAN ARAS TINGGI: MENYEJAHTERAKAN MASYARAKAT MADANI
}

\author{
NOOR ROHANA MANSOR
}

Department of Language and Communication, Center for Foundation and Continuing Education, Universiti Malaysia Terengganu (UMT), Terengganu, Malaysia

*Corresponding author: noor_rohana@umt.edu.my

Submitted final draft: 25 May $2020 \quad$ Accepted: 24 August $2020 \quad$ http://doi.org/10.46754/jbsd.2020.09.008

\begin{abstract}
Abstrak: Masyarakat Madani Mengangkat Martabat Ummah memperlihatkan pernyataan tema yang sarat dengan maksud yang indah untuk dislogankan namun perlukan tindakan yang wajar untuk direalisasikan. Apatah lagi dalam keunikan masyarakat Malaysia yang mempamerkan kepelbagaian kaum, budaya dan agama, masih hidup dalam suasana harmoni. Namun, sejauh manakah Malaysia telah mencapai pembentukan sebuah masyarakat madani? Madani yang diertikan sebagai masyarakat yang maju dari segi pemikiran, kerohanian dan kebendaan serta beradab dan menyanjung tinggi nilai-nilai kemanusiaan. Menggarap pengertian ini memerlukan kekuatan dari akar umbi - individu, keluarga dan kumpulan yang membentuk masyarakat keseluruhannya. Pastinya kepelbagaian fokus dan aspek perlu diberi perhatian serius bagi merealisasikannya. Antaranya ialah agenda transformasi pendidikan negara dengan penekanan utama untuk mengembangkan potensi pemikiran aras tinggi pelajar perlu diupayakan dalam kalangan setiap individu yang menjadi elemen asas mencipta masyarakat madani. Matlamatnya untuk melahirkan generasi yang berupaya untuk mengurus tadbir akal dan fikiran dalam menangani pelbagai cabaran kehidupan dengan berkesan. Justeru, kertas kerja ini mengupas dan merungkaikan Model Kerangka Asas Berfikir yang telah diresolusikan untuk membudayakan pemikiran aras tinggi hasil daripada penyelidikan berterusan dalam pengajaran dan pembelajaran bahasa dan merentas kurikulum pendidikan penggunaannya. Upaya untuk merealisasikan pemikiran aras tinggi pelajar dari akar umbi dalam pendidikan baik di peringkat rendah, menengah mahupun pengajian tinggi, model ini wajar difahami dan dihayati serta dipraktiskan dan diterapkan dalam pengajaran dan pembelajaran. Penghayatan ilmu dan penguasaan kemahiran pemikiran aras tinggi dalam kalangan individu menjadi pemangkin ke arah pembentukan masyarakat madani yang maju, berkat dan sejahtera dalam mengangkat martabat ummah.
\end{abstract}

Kata kunci: Masyarakat Madani, Pemikiran Aras Tinggi, Model Kerangka Asas Berfikir.

\section{Strengthening High Level Thinking: Prospering The Civil Society}

\begin{abstract}
Madani Society Upholds the Dignity of the Ummah shows a statement of themes that need a reasonable action to be realized. To what extent has Malaysia reached the formation of a Madani society? This understanding requires strength from grassroots that make up the whole community. The diversity of focus and aspects needs to be given serious attention to make it happen. Among them are the country's educational transformation agenda that emphasis on developing the potential of high-level students thinking within
\end{abstract}


each individual who is a fundamental element of creating a madani society. The goal is to produce a generation capable of managing the mind in dealing with various challenges effectively. This paper disseminates and elaborates on the Basic Thinking Framework Model which has been proposed to cultivate highlevel thinking as a result of ongoing research in language teaching and learning across curriculum. In an effort to realize students' high-level thinking from the grassroots education, this model should be understood, internalized, and applied in teaching and learning. Engagement of the knowledge and mastery of highlevel thinking skills among individuals are the catalyst towards the formation of a prosperous madani society in elevating the dignity of the ummah.

Keywords: Madani society, high level thinking, basic thinking framework models

\section{Pengenalan}

Pembentukan masyarakat madani yang diertikan sebagai masyarakat yang maju dari segi pemikiran, kerohanian dan kebendaan serta beradab dan menyanjung tinggi nilai-nilai kemanusiaan memerlukan kerjasama yang erat daripada sekecilkecil elemen masyarakat hinggalah secara kolektifnya. Menggarap pengertian ini memerlukan kekuatan dari akar umbi bermula dengan individu, keluarga dan kumpulan yang membentuk masyarakat keseluruhannya. Pastinya kepelbagaian fokus dan aspek perlu diberi perhatian serius bagi merealisasikannya. Antaranya ialah agenda transformasi pendidikan negara dengan penekanan utama untuk mengembangkan potensi pemikiran aras tinggi pelajar. Ini perlu diupayakan dalam kalangan setiap individu yang menjadi elemen asas mencipta masyarakat madani. Matlamatnya untuk melahirkan generasi yang berupaya untuk mengurus tadbir akal dan fikiran dalam menangani pelbagai cabaran kehidupan dengan berkesan selanjutnya dapat menggembeleng tenaga mewujudkan kesejahteraan dalam masyarakat keseluruhannya. Ini kerana akal dan fikiran manusia adalah kurniaan Allah SWT yang sangat berharga membezakannya daripada haiwan, perlu dicanai potensi fitrah kelahiran ini untuk membangunkan masyarakat madani yang dapat membangunkan dan mengangkat martabat ummah ke tahap terbaik. Tanpa akal dan fikiran yang waras manusia akan mudah terjerumus ke kancah konflik dan ketidaktamadunan walaupun berada pada abad yang berlandskapkan revolusi industri 4.0 .

Justeru, kertas kerja ini mengupas dan merungkaikan Model Kerangka Asas Berfikir yang telah diresolusikan untuk membudayakan pemikiran aras tinggi hasil daripada penyelidikan berterusan dalam pengajaran dan pembelajaran bahasa Melayu dan merentas kurikulum pendidikan penggunaannya. Upaya untuk merealisasikan pemikiran aras tinggi pelajar dari akar umbi dalam pendidikan baik di peringkat rendah, menengah mahupun pengajian tinggi, memerlukan kerangka model yang wajar untuk difahami dan dihayati serta dipraktiskan dan diterapkan dalam pengajaran dan pembelajaran. Penghayatan ilmu dan penguasaan kemahiran pemikiran aras tinggi dalam kalangan individu menjadi pemangkin ke arah pembentukan masyarakat madani yang maju, berkat dan sejahtera dalam mengangkat martabat ummah.

\section{Isu dan Permasalahan}

Mendepani transformasi pendidikan negara abad ke-21 kini, memerlukan komitmen pendidik sebagai pemain utama dalam memberi fokus dan memastikan potensi berfikir pelajar dibentuk ke arah menguasai kepelbagaian berfikir pada aras tinggi agar 
ia dapat direalisasikan untuk diaplikasikan dalam kehidupan sebenar nanti. Selaras dengan keperluan ini kurikulum di peringkat sekolah telah mengalami agenda transformasi bagi memastikan pemikiran aras tinggi diberi pendedahan dan dipraktikkan dalam kalangan pelajar dan juga guru. Ini telah dinyatakan secara eksplisit di dalam Pelan Induk Pendidikan Malaysia 2006-2010 (KPM, 2006) dan dilanjutkan di dalam Pelan Pembangunan Pendidikan Malaysia 2013-2025 (KPM, 2013). Transformasi ini terangkum di dalam pelaksanaan Kurikulum Standard Sekolah Rendah (KSSR) mulai 2011 dan seterusnya Kurikulum Standard Sekolah Menengah (KSSM) 2017 iaitu penambahbaikan kurikulum terdahulu KBSR (Kurikulum Baharu Sekolah Rendah) dan KBSM (Kurikulum Bersepadu Sekolah Menengah). Hakikatnya kurikulum sekolah telah melaksanakan kemahiran berfikir sacara kreatif dan kritis (KBKK) sejak tahun 1993 lagi dan kini dilanjutkan kepada kurikulum yang mengintegrasikan kemahiran berfikir aras tinggi (KBAT) merentas bidang mata pelajaran.

\section{Lanjutan}

daripada

ini

kesinambungannya di peringkat pengajian tinggi perlu direalisasikan dalam kalangan pensyarah dan juga pelajar bagi memastikan graduan yang terhasil mempamerkan citra insan yang berfikiran aras tinggi serta kompetitif menangani kehidupan abad ke21 yang kini diwarnai oleh cabaran revolusi industri 4.0. Pengajaran dan pembelajaran di IPT seharusnya mempraktiskan agenda pemikiran aras tinggi secara berleluasa merentas kurikulum bidang pengajian bagi memastikan kelahiran bakal graduan sebagai generasi pelapis dalam pelbagai organisasi negara yang mantap akal dan upaya pemikirannya. IPT perlu memberi fokus kepada tugasan akademik dan bukan akademik yang menjana idea kreatif, kritis dan inovatif; isu-isu untuk penyelesaian masalah; penghayatan ilmu untuk penggunaan serta manipulasi pengetahuan dan maklumat yang dipelajari dengan perkaitan pengalaman sedia ada yang relevan dengan situasi semasa. Generasi pelajar amat memerlukan penguasaan dan penghayatan pemikiran aras tinggi untuk menyediakan mereka menangani kehidupan yang pelbagai cabaran selepas tamat pengajian.

Namun demikian, laporan kementerian telah menjelaskan tentang penguasaan pemikiran aras tinggi dalam kalangan guru dan murid di Malaysia amat rendah. Ini telah dibuktikan melalui kedudukan negara yang belum mencapai tahap membanggakan dalam Trends in Mathematics and Science Study (TIMMS) 2007 dan Program for International Student Assessment (PISA) 2010 serta laporan kajian keperluan oleh Perunding Kestrel Education (UK) dan 21 Century Schools (USA) pada 2011. Ekoran daripada ini pihak KPM telah memantapkan usaha ke arah menghasilkan modal insan yang kreatif dan berinovatif bagi menghadapi cabaran pendidikan abad ke-21 yang memerlukan seseorang yang mampu berfikir pada aras tinggi dengan kerjasama Agensi Inovasi Malaysia di bawah Jabatan Perdana Menteri melaksanakan program i-THINK yang bertujuan mempertingkatkan dan membudayakan kemahiran berfikir dalam kalangan murid ke arah menghasilkan murid berinovatif dan telahpun terlaksana di semua sekolah pada tahun 2014. Guru dan murid dipraktikkan menggunakan alat berfikir dalam pengajaran dan pembelajaran di samping melaksanakan aktiviti kemahiran berfikir aras tinggi. Senario ini menunjukkan keseriusan pendidikan negara dan betapa banyaknya pelaburan telah dibuat dalam memastikan generasi yang dihasilkan berupaya mencitrakan budaya berfikir pada aras tinggi.

Secara teknikalnya di peringkat sekolah, kajian berterusan telah membuktikan kelemahan dalam pemahaman dan penguasaan pemikiran aras tinggi pelajar (Noor Rohana Mansor; 
2011, 2013 \& 2016). Kelemahan pelajar yang amat nyata ialah dari segi ketiadaan idea yang bernas; tiada unsur kemahiran berfikir kreatif dan kritis iaitu tidak dapat memberi alternatif fikiran serta alasanalasan yang munasabah dan relevan dengan pertanyaan; idea dan pendapat yang diberi terhad dan tidak global disebabkan kurang pembacaan meluas terhadap isu-isu semasa; pendapat yang diberikan juga tidak matang; gagal memberikan pendapat dan pandangan sendiri, malah jawapan masih terikat dengan idea teks yang diberi. Tegasnya keupayaan akal dan fikiran pelajar masih berada pada tahap rendah dan masih belum menguasai aras pemikiran tinggi untuk menghasilkan kupasan jawapan yang bernas.

Lanjutannya di peringkat pengajian tinggi isu berkaitan penguasaan dan pengaplikasian aspek pemikiran aras tinggi dalam pengajaran dan pembelajaran juga implementasi pedagogi turut dialami. Impaknya memberi kesan kepada graduan mempraktikkannya dalam industri sebenar setelah bergraduat. Kelemahan yang dikenal pasti antaranya ialah dalam aspek penjanaan idea untuk menyelesaikan tugasan yang diberi, menghasilkan ciptaan baharu, mengaplikasikan ilmu pengetahuan dalam pelbagai situasi yang berlainan untuk menyelesaikan masalah yang timbul dalam kehidupanharian secarakreatifdan praktikal; gagal memberi dan menyatakan alasan serta bukti yang wajar sebagai justifikasi kepada cadangan yang dikemukakan dalam proses pembelajaran dan dalam kehidupan harian; malah penekanan kuliah masih kepada pemahaman dan penghafalan fakta berbanding aspek kemahiran berfikir (Yee, et al. 2010; Mohd Yusof, 2007; Tan \& Samyudia, 2009; Graham \& McKenzie, 1995; Phillips, 2004; Yusof, Othman \& Karim, 2005; Candy, Crebert \& O' Leary, 1994; Sirat et al., 2004; Mustaffa, 2007; Richmond, 2007; Karim, 1994; Syed Mohd Yamin, 2007).

Telah dikenal pasti juga pedagogi dalam kalangan pendidik perlu dibawa kepada wacana kemahiran berfikir aras tinggi seandainya transformasi pengajaran dan pembelajaran ke arah pemikiran aras tinggi menjadi agenda untuk direalisasikan. Hasil kajian telah membuktikan praktis pengajaran dan pembelajaran semasa kuliah oleh sesetengah pengajar di IPT menghadapi masalah untuk menerapkan pemikiran aras tinggi dalam membangunkan kemahiran berfikir pelajar dan aktiviti pembelajaran pelajar tidak melibatkan proses metakognitif. Malah ada pengajar yang memilih kaedah pengajaran berpusatkan kuliah dalam menyampaikan kandungan pelajaran dan meliputi sukatan pelajaran untuk memenuhi keperluan peperiksaan manakala proses pengajaran dan pembelajaran lebih berfokus kepada pemikiran aras rendah (Rajendran, 2001; Ball \& Garton, 2005; Shuib, 2007; Jimenez \& Diaz, 1997; Whittington et al. 1997; Mladenovic, 2001; Mohd \& Hassan, 2006; Jones, 2010; Mustaffa, 2007; Md Yunos et al., 2011; Yee et al. 2012). Hakikatnya, untuk merealisasikan transformasi pendidikan ke arah menggilap potensi pemikiran pelajar kepada pemikiran aras tinggi perlu mempunyai aktiviti penyelesaian masalah yang bukan sahaja melibatkan pemikiran yang logik dan rasional tetapi juga melibatkan pemikiran yang boleh diaplikasikan dalam keadaan sebenar.

Justeru, isu dan permasalahan yang dipaparkan adalah serius, dialami baik di peringkat sekolah sehingga ke institusi pengajian tinggi. Keseriusan ini perlu ditangani dari akar umbi bagi memastikan potensi berfikir pelajar dibentuk sejak dari awal perkembangannya. Agenda kegagalan penguasaan pemikiran aras tinggi dalam kalangan pelajar telah sekian lama dihebahkan. Namun resolusi kepada isu tersebut hingga kini masih berterusan dan jika dibiarkan akan menjadi parah. Natijahnya pelajar perlu diberi kerangka asas untuk berfikir dengan jelas supaya 
mereka sedar hala tuju untuk berfikir, proses dan tindakan yang wajar dilalui sehingga menghasilkan resolusi yang pelbagai dalam apa jua situasi yang bakal ditempuhi baik untuk membuat keputusan, menyelesaikan masalah mahupun menjana idea. Pengalaman inilah yang dapat membuka minda pelajar untuk menghayati dan menjiwai ilmu dengan penghayatan yang tinggi semasa sesi pengajaran dan pembelajaran malah melakukan aktiviti berfikir yang berkesan untuk diri, keluarga, masyarakat dan agama.

\section{Tinjauan kajian}

Bagi mencapai matlamat keintelektualan pelajar secara khusus kandungan input dan pelaksanaan kurikulum pendidikan negara wajar memberi penegasan kepada proses kemahiran berfikir pada aras tinggi dalam implementasi pengajaran dan pembelajaran. Hakikatnya, akal untuk berfikir digerakkan oleh soalan dan untuk menggerakkan pemikiran, penggunaan soalan hendaklah merangsang minda pelajar. Inilah asas yang menjadi komitmen kurikulum pendidikan negara yang memerlukan transformasi dan penilaian semula ke arah melahirkan pelajar yang proaktif inteleknya dan cemerlang prestasinya dalam menguasai ilmu pengetahuan dan meneruskan kehidupan. Penegasan ini memberi provokasi kepada pendidik untuk menggerakkan pelajar ke arah berfikir pada kepelbagaian aras pemikiran khususnya aras tinggi. Dalam hal ini, para pendidik memikul amanah, tanggungjawab dan peranan sebagai ultimate basic untuk menggunakan soalansoalan yang berkualiti iaitu soalan yang pelbagai aras dengan tumpuan kepada soalan-soalan aras tinggi serta berupaya merangka strategi penyoalan yang mantap dan berkesan. Penggunaan soalan dan penyoalan dalam konteks pendidikan bukan hanya untuk menguji kefahaman pelajar semata-mata. Malah lebih jauh daripada itu soalan-soalan yang dibina dengan pelbagai aras kognitif dan digunakan dengan perancangan rapi semasa sesi pengajaran dan pembelajaran akan dapat membentuk paradigma pemikiran yang pelbagai dalam kalangan pelajar serta berupaya menghasilkan pembelajaran yang lebih berkesan. Implementasi ini akan memberi kesan kepada pembentukan pemikiran individu yang cemerlang pemikiran dan keintelektualannya (Noor Rohana Mansor, 2013). Justeru, peranan pendidik amat penting untuk mengaplikasikan pengetahuan mereka bagi membantu pelajar menguasai pemikiran aras tinggi (Whiteley, 2006).

Senario di sekolah dalam konteks implementasi pedagogi bahasa, telah dilaporkan beberapa dapatan yang perlu diberi perhatian serius untuk membawa pengajaran dan pembelajaran bahasa Melayu khususnya ke tahap pemikiran aras tinggi. Dapatan kajian menemui kebanyakan wacana pengajaran dan pembelajaran adalah di aras rendah; medium pengajaran tidak kreatif dan tidak dapat mengembangkan kemahiran berfikir aras tinggi dalam kalangan pelajar (Rajendran, 2002; Khairul Arifin, 2002; Seman Salleh, 2005). Dalam hal ini pendidik bahasa disaran untuk menggunakan pendekatan terbaik dalam membantu pelajar untuk belajar bahasa secara bermakna dan memperkembangkan pemikiran aras tinggi mereka. Kalangan pendidik perlu sedar bahawa pelajar telah mempunyai kefahaman intuitif tentang bahasa dan tidak hadir ke sekolah secara vacuum. Mereka menggunakan pengetahuan informal tentang bahasa dan pelbagai strategi yang boleh diramal dalam menyelesaikan masalah sedangkan mereka masih belum diajar secara formal cara berbahasa yang abstrak dalam menyelesaikan masalah. Tegasnya pembelajaran bahasa secara formal berlaku di sekolah dan amanah ini dipertanggungjawabkan kepada kalangan pendidik bagi memastikan pelajar-pelajar dapat mempelajari bahasa 
Melayu dengan sebaik-baiknya. Amat penting kalangan pendidik menerapkan kemahiran berfikir aras tinggi dengan memberi pendedahan kepada pelajar untuk memahami, menangani, menganalisis, menterjemah, dan memanipulasikan maklumat (Rajendran, 2002). Ini kerana sesuatu persoalan yang perlu dijawab atau masalah yang perlu diselesaikan tidak boleh diselesaikan dengan menggunakan kaedah rutin. Kemahiran berfikir aras tinggi memerlukan pelajar menilai maklumat secara kritis, membuat inferens dan membuat generalisasi. Lantas, dalam usaha menggerakkan pelajar menguasai pemikiran aras tinggi secara rasional, kreatif, kritis dan inovatif, soalan-soalan aras tinggi perlu dimanipulasikan dalam konteks perkembangan kurikulum pendidikan negara ke arah merealisasikan keupayaan keintelektualan pelajar untuk berfikir secara berkesan menerusi implementasi soalan secara sistematik (Noor Rohana Mansor, 2013).

Begitu juga di peringkat pengajian tinggi, kajian-kajian lepas telah menyentuh pelbagai isu pedagogi dalam pelaksanaan pengajaran dan pembelajaran. Antaranya telah dikenal pasti sesetengah pengajar di IPT menghadapi masalah membangun kemahiran berfikir pelajar (Shuib, 2007). Penyelidikan-penyelidikan oleh Ball dan Garton (2005), Jimenez dan Diaz (1997) dan Whittington et al. (1997) juga menjelaskan kebanyakan pengajar tidak tahu bagaimana menerapkan kemahiran berfikir aras tinggi kepada pelajar manakala ada yang tidak sanggup melaksanakannya. Pelajar menghadapi masalah kekurangan garis panduan yang jelas ke atas pengaplikasian kemahiran berfikir dalam proses pembelajaran dan dalam kehidupan harian. Begitu juga bagi Rajendran (2001) mendapati perkembangan kemahiran berfikir kurang diberi penekanan dan pengajaran kemahiran berfikir yang spesifik dalam kalangan pelajar masih kurang berlaku. Malah, Ng (2004), Idris
(2002), Collin et al., (1989) menjelaskan bahawa kebanyakan sumber pendidikan tidak mengambil kira pembangunan kemahiran berfikir aras tinggi dan aktiviti pembelajaran pelajar tidak melibatkan proses metakognitif. Penerapan ilmu pengetahuan mengikut aras taksonomi kognitif yang tertinggi kurang berlaku (Mohd Yusof, 2007) manakala proses pengajaran dan pembelajaran lebih berfokus kepada pemikiran aras rendah (Mohd \& Hassan, 2006). Natijahnya sistem pendidikan yang berjaya harus mempunyai aktiviti penyelesaian masalah yang bukan sahaja melibatkan pemikiran yang logik dan rasional tetapi juga melibatkan pemikiran yang boleh diaplikasikan dalam keadaan sebenar.

Terkini, Noor Rohana Mansor (2019) berdasarkan kesinambungan kajian pemikiran aras tinggi beliau merumuskan dapatan, keupayaan pemikiran aras tinggi pelajar memerlukan pendedahan kepada strategi yang khusus dan wajar untuk membolehkan mereka menguasai dan mencapai kemahiran dalam mengaplikasikan aras pemikiran tersebut. Pelajar perlu mengetahui, memahami, menguasai dan menghayati kerangka elemen-elemen asas dalam kemahiran berfikir di samping keupayaan bahasa dan berbahasa untuk membolehkan mereka berketerampilan dalam penyampaian serta penjelasan idea yang berkesan. Persoalannya bagaimana untuk berada pada aras pemikiran tinggi? Rata-rata hasil kajian terdahulu menjelaskan tentang pelbagai isu yang dihadapi dalam aplikasi pengajaran dan pembelajaran untuk menerapkan aspek pemikiran aras tinggi kepada pelajar. Malah pelajar sendiri menjelaskan mereka tidak diajar dan tidak tahu bagaimana untuk mengaplikasikan pengetahuan, kemahiran dan nilai yang perlu diterjemahkan dengan penguasaan pemikiran pada aras tinggi. Tinjauan umum dalam kalangan pendidik menunjukkan $90 \%$ hanya menyampaikan kuliah dengan latihan rutin yang ringkas 
untuk memenuhi keperluan silibus pengajian tanpa menerapkan aktiviti yang menjana elemen kemahiran berfikir aras tinggi. Bagi pelajar pula tinjauan menjelaskan mereka bosan mendengar pensyarah menyampaikan kuliah sahaja tanpa melibatkan aktiviti yang menerapkan elemen-elemen pemikiran aras tinggi yang seharusnya mereka kuasai. Jelas mereka pemikiran aras tinggi tidak diaplikasikan dalam sesi pengajaran dan pembelajaran lantas mereka tidak tahu bagaimana untuk mencapai aras tersebut. Aktiviti yang menjurus kepada persoalan bagaimana untuk menguasai ilmu untuk berfikir pada aras tinggi malah pelbagai aras sekalipun tidak diajar atau diterapkan di dalam pengajaran dan pembelajaran. Pengajaran dan pembelajaran seharusnya berada pada realiti iaitu dengan melibatkan pelajar dalam konteks menghayati ilmu untuk berfikir dan menguasai kemahiran dalam pelbagai aras berfikir khususnya pada pemikiran aras tinggi bagi membolehkan mereka menyampaikan idea penyelesaian masalah dengan mantap dan berkesan.

Justeru, hasil kajian terdahulu menjadi landasan yang kukuh menyedarkan kalangan pendidik pada semua tahap pengajian untuk menyediakan pelajar kepada situasi mengenali dan menghayati ilmu berhubung kerangka asas untuk berfikir khususnya pada aras tinggi dengan jelas. Ini selanjutnya dapat mengupayakan mereka untuk mengaplikasikannya dalam pelbagai situasi yang mendepani kehidupan mereka dengan sewajarnya dalam mengambil tindakan.

\section{Metodologi kajian}

Kajian ini mengaplikasikan Soft System Methodology (SSM) dan menyediakan platform untuk memberi tumpuan kepada isu-isu berkaitan pemikiran aras tinggi, memeriksa andaian pihak berkepentingan, dan memahami unsur-unsur soalan dan penyoalan aras tinggi di peringkat pendidikan menengah dan lanjutan di IPT yang perlu diperkemaskan. Teknik meta analisis ringkas dengan berfokus kepada rangkuman dapatan kajian primer penyelidik yang lepas berhubung aspek pencapaian pemikiran aras tinggi pelajar dalam memahami dan menyampaikan idea dengan alasan yang munasabah bagi penyelesaian isu dan permasalahan diaplikasikan. Sampel kajian peringkat sekolah melibatkan 683 pelajar sekolah kurikulum perdana (372) dan kurikulum dwialiran (311) manakala peringkat pengajian tinggi kursus elektif melibatkan 53 orang. Analisis data secara diskriptif ini meninjau dan menilai prestasi keupayaan berfikir aras tinggi pelajar peringkat menengah serta lanjutannya di institusi pengajian tinggi dalam pengajaran dan pembelajaran bahasa Melayu untuk memanipulasikan operasi berfikir yang pelbagai aras dalam aspek pemahaman serta penyampaian idea dengan alasan yang wajar bagi penyelesaian isu yang diberi. Penggunaan SSM akan mengenal pasti sejauh mana pengetahuan dan keperluan pihak berkepentingan dalam isu pemikiran aras tinggi serta menyumbang input untuk mereliasasikan tranformasi pembelajaran di sekolah dan universiti ke arah pemikiran aras tinggi. Pada akhir proses SSM Model Kerangka Asas Berfikir diperkenalkan sebagai panduan yang jelas untuk penguasaan dan pengaplikasian kemahiran berfikir aras tinggi dalam sistem pendidikan negara.

\section{Dapatan dan Perbincangan}

Penguasaan Pemikiran Aras Tinggi Peringkat Sekolah

Hasil tinjauan dan penilaian secara khusus berhubung aspek pencapaian pemikiran aras tinggi pelajar dalam memahami dan menyampaikan idea dengan alasan yang munasabah bagi penyelesaian isu dan permasalahan dalam pengajaran dan pembelajaran bahasa peringkat sekolah dirumuskan seperti berikut: 
Jadual 1: Keupayaan pemikiran aras tinggi peringkat sekolah dalam pembelajaran bahasa

\begin{tabular}{ccccc}
\hline $\begin{array}{c}\text { Pencapaian } \\
\text { Markah }\end{array}$ & $\begin{array}{c}\text { Sekolah } \\
\text { Kurikulum } \\
\text { Perdana }\end{array}$ & \multicolumn{2}{c}{$\begin{array}{c}\text { Sekolah } \\
\text { Kurikulum } \\
\text { Dwialiran }\end{array}$} \\
\hline & $\begin{array}{c}\text { Soalan Aras } \\
\text { Penilaian }\end{array}$ & \multicolumn{2}{c}{$\begin{array}{c}\text { Soalan Aras } \\
\text { Penilaian }\end{array}$} \\
\hline & $\%$ & Bil. & $\%$ & Bil. \\
\hline Betul & 15 & 54 & 5.1 & 16 \\
Hampir & 58 & 216 & 78.5 & 244 \\
Salah & 27 & 102 & 16.4 & 51 \\
Jumlah & 100 & 372 & 100 & 311 \\
\hline
\end{tabular}

Data yang diperoleh menjelaskan keupayaan pemikiran aras tinggi pelajar masih rendah. Penilaian ini diasaskan kepada kebolehan pelajar menjawab dengan betul dan tepat bagi pertanyaan yang memerlukan pelajar memanipulasikan operasi berfikir pada aras tinggi dalam penyampaian idea yang betul dengan alasan yang wajar bagi penyelesaian isu yang diberi. Daripada jumlah keseluruhan bilangan pelajar pencapaian $15 \%$ dan $5.1 \%$ adalah sangat rendah bagi yang memperoleh markah penuh dan betul. Malah berbanding skor markah salah lebih tinggi bilangan pelajar yang mencapainya iaitu $27 \%$ dan $16.4 \%$. Kegagalan menjawab dengan markah kosong memberi impak yang serius terhadap keupayaan pelajar dalam pemahaman dan penyampaian idea pada tahap ini. Begitu juga bagi skor yang menjadi tumpuan longgokan markah pada tahap hampir iaitu yang gagal mendapat markah penuh sebanyak $58 \%$ dan $78.5 \%$. Idea telah ada dalam pemikiran mereka tetapi tidak berupaya untuk menyampaikannya dengan betul dan tepat mengikut kehendak tugasan soalan serta gagal memberikan alasan yang wajar dan selaras dengan idea yang disampaikan.
Pencapaianinimembuktikankeupayaan dan kemampuan pelajar untuk berfikir pada aras tinggi masih perlu dipupuk dan dibimbing secara serius dengan pendekatan, kaedah dan strategi yang wajar, lebih baik dan berkesan. Senario ini hakikatnya sangat membimbangkan kerana majoriti pelajar tidak berupaya untuk memahami soalan dan kehendak tugasan soalan serta memberi jawapan yang memenuhi keperluan tugasan soalan. Keupayaan akal pelajar untuk berfikir secara betul dan tepat belum dikuasai sepenuhnya. Keadaan inilah juga yang menyebabkan jawapan mereka secara majoritinya tertumpu kepada markah hampir iaitu jawapan yang diberi adalah tidak tepat dan tidak menepati dengan betul kehendak tugasan soalan. Pencapaian ini memberi implikasi bahawa lingkungan pemikiran pelajar untuk menguasai soalan-soalan pada aras tinggi telah ada tetapi tidak berjaya ditonjolkan dan dipaparkan sepenuhnya dengan jelas dalam jawapan mereka. Malah ini juga bermakna prestasi pembelajaran bahasa pelajar belum berjaya menguasai sepenuhnya keperluan-keperluan serta kemahiran untuk membentuk pemikiran pada aras tinggi sepenuhnya. Situasi ini juga menjelaskan skema pemikiran pelajar berada di dalam lingkungan yang jauh daripada keperluan jawapan dan pelajar tidak berupaya untuk mencetuskan fikiran mereka bagi mencapai kehendak soalan.

Penguasaan Pemikiran Aras Tinggi Peringkat Pengajian Tinggi

Hasil tinjauan dan penilaian secara khusus berhubung aspek pencapaian pemikiran aras tinggi pelajar-pelajar tahun akhir dalam memahami dan menyampaikan idea dengan alasan yang munasabah bagi penyelesaian isu dan permasalahan dalam pengajaran dan pembelajaran kursus elektif bahasa Melayu peringkat IPT dirumuskan seperti berikut: 
Jadual 2: Keupayaan pemikiran aras tinggi peringkat pengajian tinggi

dalam kursus elektif bahasa malayu: aspek huraian fakta

\begin{tabular}{ccc}
\hline \multirow{2}{*}{$\begin{array}{c}\text { Aspek Huraian } \\
\text { Fakta }\end{array}$} & $\begin{array}{c}\text { Pencapaian } \\
\text { Markah }\end{array}$ & $\begin{array}{c}\text { Pencapaian } \\
\text { Markah }\end{array}$ \\
& Kohort 1 & Kohort 2 \\
\cline { 2 - 3 } & Bil. $\quad \%$ & Bil. $\quad \%$ \\
\hline
\end{tabular}

Cemerlang:

$\begin{array}{lllll}\text { Huraian fakta } & 1 & 5 & 3 & 9\end{array}$

amat baik

dengan alasan

yang sangat

terperinci, tepat

dan jelas.

\begin{tabular}{lllll}
\hline Baik: & & & & \\
Huraian fakta & 7 & 33 & 9 & 28 \\
baik dengan & & & & \\
alasan yang & & & & \\
tepat dan jelas. & & & & \\
\hline
\end{tabular}

Sederhana:

$\begin{array}{lllll}\text { Huraian fakta } & 8 & 38 & 12 & 38\end{array}$

masih baik

tetapi alasan

umum dan

kurang jelas.

\begin{tabular}{lcccc}
\hline $\begin{array}{l}\text { Lemah: } \\
\text { Huraian fakta } \\
\text { lemah dan } \\
\text { alasan tidak }\end{array}$ & 5 & 24 & 8 & 25 \\
jelas. & & & & \\
\hline \multicolumn{1}{c}{ Jumlah } & 21 & 100 & 32 & 100 \\
\hline
\end{tabular}

Dapatan bagi penyampaian idea dalam konteks penghuraian dan penjelasan fakta dan maklumat sebagai justifikasi untuk sokongan idea masih perlu dipertingkatkan kemampuannya dalam kalangan pelajar. Ini kerana hasil kajian menunjukkan hanya $5 \%$ dan 9\% sahaja berjaya mencapai tahap kecemerlangan dalam penyampaian dan penghuraian fakta dan maklumat. Penjelasan yang disampaikan amat baik dengan alasan terperinci, tepat, jelas, wajar dan berkesan dengan sokongan data-data anekdot yang sangat relevan. Penggunaan bahasa yang tersusun, jelas dan mudah difahami berjaya diterapkan dalam penyampaian maklumat. Manakala $33 \%$ dan $28 \%$ masih berupaya menjelaskan maklumat pada tahap baik dengan alasan yang tepat, jelas dan wajar namun kurang sokongan data yang relevan dan menepati cadangan. Majoriti pencapaian pelajar iaitu $38 \%$ bagi kedua-dua kohort berada pada aras sederhana dengan huraian fakta dan penyampaian maklumat yang masih baik tetapi alasan yang diberikan adalah umum dan kurang jelas iaitu tidak secara khusus menjelaskan maklumat yang diberikan; kurang kewajarannya dan tidak bernas; serta tiada data anekdot yang menyokong penjelasan. Minoriti iaitu $24 \%$ dan $25 \%$ tergolong dalam kategori lemah dalam penyampaian dan penghuraian fakta dan maklumat. Alasan yang diberi kabur dan umum iaitu tidak jelas; tidak wajar dan relevan dengan idea yang dicadangkan; terpesong huraiannya dengan memberi kesan dan implikasi cadangan bukan alasan yang menyokong idea; gagal menerapkan keupayaan berfikir dengan inferensi idea yang wajar. Malah penyampaian menggunakan bahasa yang ringkas dan terhad keupayaan berbahasanya.

\section{Model Kerangka Asas Berfikir}

Justeru bagi menangani senario mengupayakan pemikiran aras tinggi pelajar potensi akal dan fikiran perlu dibentuk dan digilap pada landasan yang betul. Mereka perlu mengetahui, memahami, menguasai dan menghayati kerangka elemen-elemen asas dalam kemahiran berfikir di samping memantapkan keupayaan bahasa dan berbahasa bagi membolehkan mereka berketerampilan dalam penyampaian serta penjelasan idea yang berkesan. Hasilnya Model Kerangka Asas Berfikir diperkenalkan sebagai resolusi penulis untuk membudayakan pemikiran aras tinggi dalam pengajaran dan pembelajaran bahasa Melayu khususnya dan merentas kurikulum penggunaannya. Hasil kajian yang berterusan serta upaya untuk 
merealisasikan pemantapan kemahiran berfikir pelajar dari akar umbi dalam pendidikan baik di peringkat rendah, menengah mahupun pengajian tinggi model ini wajar dipraktiskan dan diterapkan dalam pengajaran dan pembelajaran. Model ini meletakkan lima elemen asas yang menjadi landasan untuk berfikir dengan input yang khusus bagi menggerakkan setiap elemen tersebut secara sedar. Rajah berikut menggambarkannya:

\section{Model Kerangka Asas Berfikir}

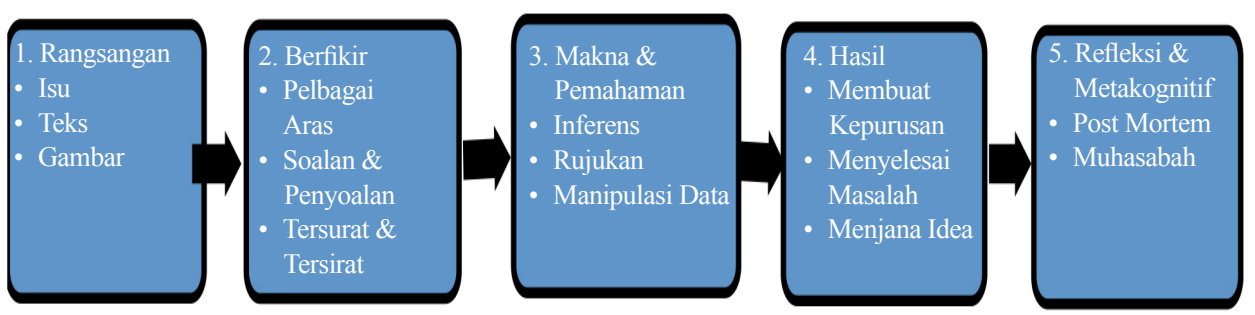

Dalam konteks untuk menjana pemikiran pelajar perlu disedarkan tentang proses yang berlaku bermula dengan rangsangan. Pelbagai rangsangan boleh menjadi penggerak untuk berfikir antaranya isu, teks dan gambar. Rangsangan akan menyedarkan pelajar untuk berfikir tentang keperluan tugasan daripada rangsangan tersebut. Dalam konteks pelajar berfikir pendedahan tentang kepelbagaian aras berfikir rendah dan tinggi berasaskan taksonomi Bloom atau seumpamanya perlu dikuasai. Gerakkan pemikiran untuk berfikir menggunakan soalan dan penyoalan malah pelajar perlu bezakan berfikir secara tersurat dan tersirat untuk mendapat makna dan pemahaman yang lanjut. Ini akan membawa kepada elemen untuk mencari makna dan pemahaman. Di sinilah pelajar perlu diajar untu membuat inferens, rujukan serta manipulasi data dan maklumat bagi menyokong idea yang diperoleh. Selanjutnya gabungan maklumat tersebut akan memberi hala tuju untuk mendapatkan hasil daripada tugasan yang diberi sama ada untuk membuat keputusan, menyelesaikan masalah atau menjana idea bagi mencipta inovasi. Terakhir pelajar juga perlu didedahkan dengan usaha untuk membuat refleksi dan metakognitif supaya boleh menilai kembali segala tindakan yang diambil wajar, betul dan berkesan atau di sebaliknya. Kesedaran tentang aliran proses berfikir menerusi lima elemen yang menjadi kerangka asas untuk berfikir akan membolehkan pelajar menghayati keperluan dan mengambil tindakan yang wajar dalam menyampaikan idea dan maklumat. Namun demikian dalam penyampaian idea bahasa menjadi alat yang dapat menentukan keberkesanan penyampaiannya. Maka di sinilah pelajar perlu menguasai elemen-elemen asas bahasa dari segi perbendaharaan kata, morfologi, sintaksis dan semantik yang akan membawa kepada keupayaan mereka untuk berketerampilan dalam berbahasa. Jika penguasaan bahasa lemah maka akan membantutkan penyampaian idea baik secara lisan mahupun penulisan. Sebaliknya jika keupayaan bahasa dan berbahasa pelajar cemerlang maka idea akan dapat disampaikan dengan berkesan.

\section{Kesimpulan}

Memenuhi keperluan pembangunan masyarakat madani melalui agenda transformasi dan globalisasi pendidikan negara terkini, korpus terkecil masyarakat 
dalam kalangan individu iaitu pelajar dan graduan yang dihasilkan baik di peringkat sekolah mahupun institusi pengajian tinggi sewajarnya disediakan dengan keupayaan akal serta penghayatan jiwa yang kuat untuk menghadapi kehidupan yang serba mencabar. Pedagogi pengajaran dan pembelajaran secara teori dan praktis perlu digembeleng dan ditransformasikan relevan dengan perkembangan masa ke arah menjadi asas yang menggerakkan paradigma pemikiran aras tinggi dalam kalangan pelajar dengan penguasaan asas yang kukuh dalam bahasa agar berketerampilan berbahasa dalam penyampaian idea. Kerangka asas berfikir dalam pengajaran dan pembelajaran perlu diterapkan agar pelajar dapat menjiwai lantas menbudayakan kepelbagaian aras pemikiran khususnya pada aras tinggi dengan berkesan. Sasarannya agar kualiti pelajar yang bakal dilahirkan menerusi sistem pendidikan negara mampu untuk menghasilkan generasi berfikir pada aras tinggi yang berupaya untuk menangani pelbagai kerenah dan cabaran kehidupan dalam masyarakat dengan berkesan. Keupayaan ini dapat menzahirkan masyarakat madani yang dapat mengangkat martabat ummah ke arah kesejahteraan hidup dan berkualiti. Insya Allah.

\section{Penghargaan}

Pengarang mengucapkan penghargaan kepada pihak universiti, penilai dan editor di atas segala cadangan yand diberikan.

\section{Rujukan}

Ball, A. L. \& Garton, B. L. (2005). Modeling higher order thinking: the alignment between objective, classroom discourse and assessments. Journal of Agricultural Education, 46(2), 58-69.

Candy, P. C., Crebert, G. \& O' Leary, J. (1994). Developing lifelong learners through undergraduate education.
Canberra: Australian Government Publishing Service.

Graham, C. \& McKenzie, A. (1995). Delivering the promise: developing newgraduates. Education \& Training, $37(2), 33-40$.

Jimenez, A. M. P. \& Diaz, B. J. (1997). Analyzing classroom discourse: practical work in the biology laboratory. Annual Meeting of the American Educational Research Association. Chicago, IL: American Educational Research Association.

Jones, H. (2010). National curriculum tests and the teaching of thinking skills at primary schools - parallel or paradox? Education 3-13, 38(1), 69-86.

Karim, N. S. (1994). Ke arah sistem pendidikan yang unggul: cabaran \& masa depan. Dlm. Pusat Penyelidikan Strategik Malaysia. Siri Forum Ehwal Semasa MSRC 2 (hlm. 20). Kuala Lumpur: Pusat Penyelidikan Strategik Malaysia.

Khairul Arifin. (2002). Penguasaan bahasa inggeris antara kelemahan pembelajaran \& pengajaran (p\&p) atau kesilapan aliran penguasaan bahasa inggeris antara kelemahan. Berita Pendidik, Bil 106/ 2002. http://www. geocities.com/pendidikmy/berita/ fokus106.html

Md Yunos, J., Yee, M. H., Othman, W., Hassan, R., Tee, T. K. \& Mohamad, M. M. (2011). Analisis keperluan pembelajaran kemahiran berfikir aras tinggi bagi penjanaan idea. Prosiding Kongres Pengajaran dan Pembelajaran UKM 2011 (hlm. 1120). Selangor: Universiti Kebangsaan Malaysia.

Mladenovic, R. (2001). An investigation into ways of challenging introductory accounting students' negetive perceptions of accounting. Accounting Education, 9(2), 135-155. 
Mohd. A. \& Hassan, A. (2006). Pemikiran reka cipta: kaedah mengajar dan bahan latihan untuk guru dan jurulatih. pahang: PTC Publications \& Distributors Sdn. Bhd.

Mohd Yusof, N. (2007). Penggabung jalinan dan penyerapan dalam pengajaran dan pembelajaran pensyarah untuk melahirkan modal insan di ipta. Persidangan Pengajaran dan Pembelajaran Di Peringkat Pengajian Tinggi.

Mustaffa, R. (2007). Mengadaptasikan gaya pembelajaran pelajar esl: satu kajian kes pelajar tahun satu di ukm. GEMA Online Journal of Language Studies, 7(1), 1-20.

Noor Rohana Mansor. (2019). Membudayakan pemikiran aras tinggi dalam pengajaran bahasa melayu: satu cadangan resolusi. seminar antarabangsa pendidikan bahasa, sastera, dan budaya melayu kedua 2019 (SAPBaSBUM 2). 2526 Mac 2019. Universiti Goethe, Frankfurt, Jerman.

Noor Rohana Mansor. (2013). Tahap

Berfikir dalam Bahan Kurikulum

Bahasa. Kuala Terengganu:

Penerbit UMT. ISBN 978-967-0524-

21-4.

Noor Rohana Mansor. (2019). Modul pengajaran-pembelajaran BBB3105 kemahiran berfikir. Kuala Terengganu: Penerbit UMT. ISBN 978-967-232028-9.

Pelan Strategik Interim Kementerian Pelajaran Malaysia 2011-2020. (2012). Putra Jaya: Kementerian Pelajaran Malaysia.

PPPM 2013-2025. (2013). Putra Jaya: Kementerian Pelajaran Malaysia.

Phillips, J. A. (2004). Keberkesanan pengajaran kemahiran berfikir: perubahan kepada sistem persekolahan.
Keynote Paper, Seminar Kebangsaan Pengajaran Kemahiran Berfikir: Tinjauan Kejayaan Satu Dekad. Shah Alam: 201 Universiti Pendidikan Sultan Idris \& Bahagian Pendidikan Guru, Kementerian Pendidikan Malaysia.

Rajendran, N. S. (2001). Pengajaran kemahiran berfikir aras tinggi: persediaan guru mengendalikan proses pengajaran pembelajaran. Seminar/ Pameran Projek KBKK: 'WarisanPendidikan-Wawasan'. Kuala Lumpur: Pusat Perkembangan Kurikulum, Kementerian Pendidikan Malaysia.

Rajendran, N. S. (2002). Bahasa melayu: penyumbang ke arah penguasaan pemikiran aras tinggi. Universiti Pendidikan Sultan Idris: Tanjong Malim. http://nsrajendran.tripod.com/ Papers/beijing2002.pdf

Richmond, J. E. D. (2007). Bringing critical thinking to the education of developing country professionals. International Education Journal, 8(1), 1-29.

Seman Salleh. (2005). Pelaksanaan pengajaran dan pembelajaran bahasa melayu: kajian kes di sebuah sekolah rendah di daerah jerantut, pahang darul makmur.http://apps.emoe.gov.my/ ipba/ResearchPaper/journal/article3. pdf

Shuib, M. (2007). Developing undergraduates' thinking skills. Prosiding Persidangan Pengajaran dan Pembelajaran di Peringkat Institusi Pengajian.

Sirat, M., Buang, A. A., Mohd. Isa, A. M., Pandian, A., Abdullah, M. A., Ibrahim, M. D., Piei, H., Lee, M. N. N., Shuib, M., Bakar, R., Mustafa, R., Abdul Rahman, S., A. Hamid, S. Z., See, S. C. M. \& Kamil Mahmood, W. A. (2004). Kajian masalah pengangguran di kalangan siswazah. Pulau Pinang:Institut Penyelidikan 
Pendidikan Tinggi Negara (IPPTN), Universiti Sains Malaysia.

Syed Mohd Yamin, S. S. (2007). Kemahiran berfikir yang dominan di kalangan pelajar politeknik dan hubungannya dengan pencapaian pelajar. Universiti Tun Hussein Onn Malaysia: Tesis Sarjana.

Tan, Y. L. \& Samyudia, Y. (2009). Learning styles versus teaching styles: how to match them? teaching and learning open forum. Sarawak: Curtin University of Technology.

Whiteley, T. R. (2006). Using the socratic method and bloom's taxonomy of the cognitive domain to enhance online discussion, critical thinking, and student learning. Developments in Business Simulation and Experiential Learning Journal, 33. http://sbaweb. wayne.edu/ absel/bkl/vol33/33ai.pdf

Whittington, M. S., Stup, R. E., Bish, L., \& Allen, E. (1997). Assessment of cognitive discourse: a study of thinking opportunies provided by professors.
Journal of Agricultural Education, $38(1), 46-53$.

Yee, M. H., Md Yunos, J., Othman, W., Hassan, R., Tee, T. K. \& Mohamad, M. M. (2012). The needs analysis of learning higher order thinking skills among technical students. Proc. of the 3rd International Conference on Education and Educational Psychology (ICEEPSY 2012). Turkey: Istanbul.

Yee, M. H., Jailani, M. Y.,Noraini, O., Suzanna, I., Tee, T. K. (2010b). "The perception of student on mastering the level of higher order thinking skills in technical education subjects." Proceeding The 3rd Regional Conference on Engineering Education \& Research in Higher Education 2010. Skudai, Johor: Universiti Teknologi Malaysia.

Yusof, R., Othman, N. \& Karim, F. (2005). Strategi pembelajaran pengalaman berasaskan model kolb dalam pendidikan perakaunan. Jurnal Pendidikan, 30, 113-128. 
